\title{
ARTIGOS
}

Recebido em 12.08.2013. Aprovado em 02.01.2014

Avaliado pelo sistema double blind review. Editora Científica: Janette Brunstein

DOI: http://dx.doi.org/10.1590/So034-759020150209

\section{CRIMES CORPORATIVOS E ESTUDOS ORGANIZACIONAIS: UMA APROXIMAÇÃO POSSÍVEL E NECESSÁRIA}

\author{
Corporate crimes and organizational studies: a possible and necessary \\ approach
}

\author{
Crímenes corporativos y estudios organizacionales: una aproximación \\ posible y necesaria
}

\begin{abstract}
RESUMO
Escândalos corporativos têm sido comuns na sociedade contemporânea. Nesse contexto, os crimes cometidos nas e por corporações também tomam vulto e, frequentemente, tomamos conhecimento de um tipo de crime corporativo, um tema não explorado em pesquisas nos estudos organizacionais. Neste estudo, realizamos uma síntese de pesquisas sobre crimes corporativos com o objetivo de buscar uma aproximação do tema com o campo dos estudos organizacionais. Desenvolvemos o artigo sinalizando para a predominância da abordagem moderna em estudos sobre o tema e, ao final, propomos perspectivas alternativas para a análise da criminalidade corporativa no âmbito dos estudos organizacionais.
\end{abstract}

PALAVRAS-CHAVE | Crime corporativo, estudos organizacionais, corporações, poder, lado sombrio das organizações.

\begin{abstract}
Corporate scandals have been common in contemporary society. In this context, the crimes committed in and by corporations also take form, and often we get to know a type of corporate crime, a topic not explored in organizational studies. In this study, we conducted a synthesis of researches on corporate crime with the purpose to seek an approach to the theme on the organizational field. We developed an article signaling to the predominance of modern approach to the studies on the matter, and finally, we proposed alternative perspectives for the analysis of corporate criminality in the context of organizational studies.
\end{abstract}

KEYWORDS / Corporate crime, organizational studies, corporations, power, dark side of organizations.

\section{RESUMEN}

Escándalos corporativos han sido comunes en la sociedad contemporánea. En ese contexto, los crímenes cometidos en las y por las corporaciones también han aumentado y, frecuentemente, tomamos conocimiento de un tipo de crimen corporativo, un tema no explorado en pesquisas sobre los estudios organizacionales. En ese estudio, realizamos una síntesis de pesquisas sobre crímenes corporativos con el objetivo de buscar una aproximación del tema con el campo de los estudios organizacionales. Desarrollamos el artículo señalando a la predominancia del abordaje moderno en estudios sobre el tema y, al final, proponemos perspectivas alternativas para el análisis de la criminalidad corporativa en el ámbito de los estudios organizacionales.

PALABRAS-CLAVE / Crimen corporativo, estudios organizacionales, corporaciones, poder, lado sombrío de las organizaciones. 


\section{INTRODUÇÃO}

No mesmo compasso em que as corporações assumiram certo protagonismo na sociedade contemporânea, por um lado, gerando expectativas e, de outro, questionamentos quanto à sua atuação, a criminalidade corporativa passou a ser analisada por sociólogos criminologistas como um fenômeno complexo sobre o qual questões conceituais e analíticas ainda permanecem sem respostas (Payne, 2012; Shover \& Hochstetler, 2002). A expressão crime corporativo tem sido largamente utilizada, nas últimas décadas, como referência a práticas e condutas que violam as leis criminais envolvendo corporações. Todavia, ainda que tenha despertado o interesse dos estudiosos no campo da sociologia e da criminologia há mais de 50 anos (Braithwaite, 1985; Szwajkowski, 1985), o crime corporativo tem sido pouco explorado na literatura (Payne, 2012; Snider, 2000), sendo ainda um território desconhecido no campo dos estudos organizacionais.

Neste artigo, realizamos uma revisão teórica sobre os crimes corporativos com o objetivo de buscar uma aproximação com os estudos organizacionais, visto que esses constituem-se em eventos que ocorrem no âmbito da gestão e das organizações, os quais são objetos de estudo desse campo.

Inicialmente, apresentamos uma síntese das pesquisas realizadas sobre crimes corporativos. Em seguida, buscamos situar o tema no campo dos estudos organizacionais, propondo a adoção de perspectivas alternativas àquelas já existentes. Encerramos o artigo com as considerações finais, apresentando uma agenda de pesquisa sobre o tema no âmbito dos estudos organizacionais.

\section{CRIMES CORPORATIVOS: PESQUISAS E SUAS ABORDAGENS}

Desde o discurso presidencial de Sutherland na American Society of Sociology, em 1939, quando introduziu o termo White Collar Crime, os business crimes ou crimes corporativos passaram a fazer parte da agenda de criminologistas e sociólogos, embora timidamente, os quais percorreram caminhos ora distintos, ora convergentes, adotando nomenclaturas e níveis de abordagens diferentes (Payne, 2012). Sutherland definiu o termo como "um crime cometido por uma pessoa de respeitabilidade e de alto status social no curso de sua ocupação" (Sutherland, 1949, p. 9), gerando polêmicas que renderam outras publicações para desenvolver o conceito de white collar crime e torná-lo uma construção mais sólida no campo da sociologia (Braithwaite, 1985).
Em que pesem todas as críticas a Sutherland, Braithwaite (1985) e Geis (1991), entre outros, chamam a atenção para o legado desse autor. Braithwaite (1985, p. 12) entende que "A literatura sobre white collar crime contribuiu significativamente para nosso entendimento do modo como as enormes desigualdades de classe são mantidas [...]". Geis (1991, p. 17), por sua vez, mostra-se convencido de que Sutherland "focalizou uma questão de singular importância intelectual e prática - o abuso do poder por pessoas que estão situadas em posições relativamente altas onde elas estão providas da oportunidade para tal abuso". Ainda, o corpo de conhecimento sobre um tipo de crime que ocorre com mais intensidade que os crimes comuns tornou-se uma realidade para a sociologia jurídica.

Sutherland $(1940,1941,1949)$ não articulava suas ideias como jurista, mas, sim, como sociólogo. 0 autor não coadunava com a noção dogmática de crime, construindo um conceito que, pelos padrões das definições tradicionais, não se enquadrava como tal, portanto a sua concepção sobre o crime em geral e, em particular, sobre white collar crime, é de natureza sociológica. 0 olhar lançado por Sutherland para esse fenômeno é orientado pela tentativa de compreender a sociedade e o seu comportamento diante dos problemas que a afligem.

Muitos termos são utilizados como sinômino de crime corporativo. Para Clinard Yeager, Brissette, Petrashek e Harries (1979, p. 17), o crime corporativo é aquele que "ocorre no contexto do complexo e variado conjunto de relacionamentos e inter-relacionamentos estruturados entre o corpo de diretores, executivos, e gerentes de um lado e empresas-mãe, divisões corporativas e subsidiárias de outro". Kramer (1984, p. 18) esclarece que o termo compreende "atos criminais (de omissão ou comissão) que são resultado de ações tomadas deliberadamente (ou negligência culposa) por aqueles que ocupam posições na estrutura da organização como executivos ou gerentes" motivados pelos objetivos corporativos.

Outras denominações são utilizadas para referir-se a crime corporativo, como ilegalidade corporativa (Baucus, 1994) e má conduta organizacional (MacLean, 2008), conforme a concordância dos autores quanto à necessidade de condenação pela corte para o crime ser denominado como tal e, ainda, quanto a esse ser uma conduta ilegal, e não propriamente um crime prescrito por lei.

Os estudos sobre antecedentes e determinantes do crime corporativo são, em grande parte, derivados das teorias organizacionais, visto que são essas que oferecem explicações mais específicas sobre o que ocorre no âmbito das organizações. Esses estudos foram realizados por criminologistas e sociólogos que consideraram as micro, meso ou macrofundações sobre as organizações e sobre a criminalidade, muitos deles 
privilegiando uma abordagem isolada, e outros propondo uma perspectiva integrativa para analisar as causas e o processo da criminalidade corporativa (ver Mon, 2002; Payne, 2012).

Szwajkowski (1985), por exemplo, propõe a análise dos estímulos à ilegalidade organizacional por meio da integração teórica de três variáveis determinantes para a sua ocorrência que, comumente, convergem nos estudos sobre o tema, a saber: (1) ambiente (pressões, necessidade ou recessão econômica); (2) estrutura (corporativa, industrial ou legal); e (3) processo de escolha interna (patologia, intenção ou exploração proativa).

Na busca de uma explicação mais profunda para o assunto, Coleman (1987) propõe uma perspectiva integradora para a pesquisa das origens do White Collar Crime, partindo da pressuposição de que o comportamento criminal é resultado da confluência entre a motivação adequada e a oportunidade. Quanto à oportunidade, Coleman (1987) observa que, mesmo o indivíduo tendo uma forte motivação para cometer o crime, esse somente ocorrerá se houver a oportunidade para tal. 0 autor analisa a aplicação da lei, a indústria, a organização e a ocupação profissional como condições objetivas sociais que estruturam a oportunidade.

A exemplo de Coleman (1987), Baucus e Near (1991) desenvolveram um modelo para análise do processo do comportamento corporativo ilegal, o qual considera os antecedentes em três níveis: ambientais, internos e situacionais. Posteriormente, Baucus (1994) ampliou a compreensão da ilegalidade corporativa ao desenvolver um modelo que considera as pressões, as oportunidades e a predisposição como antecedentes do comportamento ilegal e as características individuais como variável moderadora. 0 modelo do processo de ilegalidade corporativa proposto por Baucus (1994) considera, ainda, os tipos de ilegalidade corporativa, os quais são divididos em duas categorias: o comportamento ilegal intencional e não intencional.

Também adeptos de uma abordagem integrativa, Daboub, Rasheed, Priem, \& Gray (1995) propõem que as características da equipe de executivos da alta gestão têm relação direta com a ocorrência de atividades corporativas ilegais, ao lado de fatores externos e internos. Como fatores externos, Daboub et al. (1995) identificam as características específicas da indústria na qual a corporação atua e as características gerais do ambiente. Os fatores organizacionais ou internos considerados no modelo de Daboub et al. (1995) incluem o tamanho da empresa, a folga organizacional, a estratégia corporativa, a estrutura e sistemas de controle e a história organizacional.

O modelo de McKendall e Wagner (1997) representa um avanço aos estudos então existentes, ao considerar que a ilegalidade decorre, principalmente, dos efeitos combinados das variáveis que proporcionam motivo, oportunidade e escolha.
Quanto à escolha, constituindo-se esta em um fator moderador que age na interação do motivo e oportunidade para a conduta ilegal, McKendall e Wagner (1997) consideram o clima ético da organização capaz de estimular ou desencorajar a escolha pela conduta ilegal. Nesse sentido, antes das características pessoais, as normais sociais e características organizacionais são determinantes mais importantes para a escolha da conduta ilegal, conforme já defendido por Coleman (1987).

O estudo de Mon (2002) sobre os fatores causais da criminalidade corporativa em Taiwan considera elementos do modelo de Szwajkowski (1985), acrescentando outros, além de separar o fator individual (micro) de fatores organizacionais e institucionais (nível macro) que criam a oportunidade para o crime. Para Mon (2002, p. 187), “os crimes corporativos são eventos que ocorrem como resultado da combinação da oportunidade apropriada e indivíduos com criminalidade". Ao assumir o indivíduo como unidade de análise importante na exploração dos crimes corporativos, Mon (2002) defende que a tendência de low self-control dos indivíduos também cria a oportunidade de ocorrência do crime corporativo.

Zahra, Priem e Rasheed (2005) dirigem sua atenção para o corpo gerencial, no caso de fraudes corporativas, identificando as variáveis sociais, industriais, organizacionais e individuais que contribuem para a ocorrência desse comportamento, bem como as suas consequências para acionistas, sociedade, comunidade local, empregados e a reputação dos gestores. As fraudes podem ocorrer em qualquer nível organizacional, porém a análise dos autores recai naquelas cometidas por top managers, por esses entenderem-nas como uma modalidade do White Collar Crime. Essa análise considera que os fatores sociais, industriais e organizacionais podem encorajar e promover a fraude, ou seja, constituem-se em antecedentes à ocorrência dessa conduta. Já as características individuais atuam como moderadores, isto é, funcionam como fatores que afetam o grau das pressões desses antecedentes. 0 modelo de Zahra et al. (2005) aproxima-se bastante daquele elaborado por Mon (2002), porém avança no sentido de propor a exploração de outras características individuais que atuam como moderadores para enfraquecer ou fortalecer as pressões dos fatores antecedentes em direção à criminalidade corporativa, além da tendência de autocontrole.

MacLean (2008) adota uma perspectiva integrativa dos níveis macro e micro para analisar os crimes corporativos, ampliando o modelo tradicional de pressões e oportunidades que explicam as ocorrências desses crimes. MacLean (2008) parte de modelos teóricos (Baucus, 1994; Baucus \& Near, 1991; Daboud et al., 1995) baseados nas pressões e oportunidades para incluir um terceiro fator, os significados compartilhados ou 
a cultura organizacional. Entendendo que a má conduta organizacional torna-se arraigada nas organizações, MacLean (2008) busca no interacionismo simbólico uma compreensão mais ampla para explicar a natureza do relacionamento entre pressões, oportunidades e a má conduta organizacional, já focalizados nas pesquisas anteriores. Essa compreensão mais ampla é necessária, como defende MacLean (2008), pelo fato de outras abordagens oferecerem explicações parciais, já que não consideram os esquemas cognitivos ou as manifestações culturais (linguagem, símbolos, imagens, estereótipos, entre outros) construídas e compartilhadas pelos membros da organização.

Em âmbito nacional, a proposta de Costa e Wood (2012) para a análise de fraudes corporativas, a qual completa o quadro dos estudos selecionados para compor esta seção, defende uma visão integrativa e processual. Embora os autores não caracterizem a fraude como crime corporativo, diversos estudos na literatura pesquisada fazem essa caracterização (e. g. Zahra et al., 2005), justificando, assim, a inclusão desse estudo nesta seção. Tomando como ponto de partida os trabalhos de Baucus (1994) e Ashforth, Gioia, Robinson e Treviño (2008), Costa e Wood (2012) elaboram sua proposta de análise, integrando cinco níveis, quais sejam: sociedade; marco regulatório; setor de atividades; organização; e indivíduo. Para Costa e Wood (2012), a compreensão de como a fraude corporativa ocorre deve considerar os fatores antecedentes e a ação de agentes que cometem as fraudes em um processo composto pelas etapas anteriormente mencionadas.

Os estudos citados abrangeram variáveis internas e externas à organização, e alguns deles buscaram compreender a criminalidade corporativa pela análise das características institucionais, organizacionais e individuais e, ainda, por etapas que compreendem uma análise processual, caracterizando-se como um corpo de conhecimento predominantemente assentado na perspectiva modernista, uma abordagem centrada no discurso do progresso e da razão (Cooper \& Burrel, 1988).

Desse modo, é possível que o conhecimento construído acerca da criminalidade corporativa tenha uma riqueza no que concerne às evidências teóricas ou empíricas dos seus fatores causais, porém trata-se de um fenômeno social complexo, cuja compreensão não prescinde de um olhar mais aprofundado sobre o modo pelo qual as corporações se constituem em atores sociais que intermediam as forças institucionais e a ação dos indivíduos. Além disso, é preciso lembrar que esse conhecimento diz respeito, principalmente, ao contexto norte-americano, cujas leis e contexto corporativo são específicos, assim como o comportamento e as reações da população a respeito dos crimes corporativos, o que impede a generalização para países como o Brasil, por exemplo.

\section{O LADO SOMBRIO DAS ORGANIZAÇÕES: DIFERENTES LENTES PARA COMPREENDER OS CRIMES CORPORATIVOS}

Os estudos organizacionais desenvolveram-se como campo de conhecimento, conforme Reed (1996), por meio de conversações e debates entre modelos e teorias explicativas, os quais surgiram em determinados contextos sócio-históricos, desenvolvendo-se de acordo com sua problemática central. Reed (1996) destaca que, nas perspectivas teóricas para interpretar a ordem, o consenso e a liberdade, predominaram o racionalismo, a manutenção da ordem e a sobrevivência organizacional, negligenciando discussões sobre as estruturas e lutas de poder dentro das organizações, bem como o poder social e a intervenção humana. Já as outras problemáticas - a dominação, o controle e a participação - privilegiaram uma ontologia realística e uma epistemologia convencionalista (Reed, 1996).

Ao identificar e analisar as problemáticas principais focalizadas pelas teorias organizacionais, Reed (1996) aponta para seus pontos de intersecção e pontos de exclusão ou de silêncio, ou seja, as omissões ou marginalização de aspectos relevantes sobre as organizações. 0 crime corporativo, principalmente, e o erro e acidentes, em menor medida, são exclusões ou marginalizações das teorias que buscam prescrições ou descrições sobre o que é a organização e sobre seu funcionamento, não se constituindo em uma problemática central para o campo.

A criminalidade corporativa, todavia, constitui-se, de fato, em uma problemática central para o campo dos estudos organizacionais, visto que, desde os anos 1970, a sociedade vem presenciando escândalos corporativos com maior frequência. Em direção a um caminho que leve à construção de um corpo de conhecimento para situar o crime corporativo no âmbito dos estudos organizacionais, buscamos perspectivas que sejam alternativas à abordagem modernista. Essa perspectiva, para o campo das organizações, significa que a ciência pode oferecer respostas para as relações causais entre a ascensão da moderna sociedade industrial e as demandas pela eficiência de métodos de gestão e as novas tecnologias (Burrel \& Cooper, 1988).

Descrevendo as organizações como instrumentos de dominação, Morgan (1996) aborda o lado sombrio das organizações, chamando-o de a face repugnante. Essa metáfora enfatiza, principalmente, o domínio ideológico das corporações que exploram e trabalhadores e nações mais pobres, ameaçam a sociedade e o meio ambiente, causam prejuízos aos consumidores e colocam a sociedade em risco. Para ocultar a sua face 
repugnante ou o seu lado sombrio, as corporações utilizam-se de um aparato ideológico para se mostrarem como sistemas racionais que perseguem objetivos dos seus stakeholders, mascarando, assim, a realidade.

Essas perspectivas, portanto, ao sinalizar para a existência de um lado sombrio das organizações, revelam-se apropriadas para a análise da criminalidade corporativa como uma das suas problemáticas centrais.A compreensão de fenômenos organizacionais não dispensa múltiplos olhares, visto que as organizações são complexas, ambíguas e multifacetadas e, portanto, abraçam problemáticas diversas com essas mesmas características. Desse mesmo modo, sendo os crimes corporativos um fenômeno organizacional, também esses requerem fontes alternativas àquelas privilegiadas em pesquisas nas quais se constituem objeto de estudo, que buscam, predominantemente, as relações causais entre o crime corporativo e características organizacionais, ambientais e individuais.

O domínio ideológico das organizações e corporações é tema na obra de diversos autores (Enriquez, 1997; Freitas, 2005; Motta, 1992; Ortega, 1999; Pagés, Bonetti, Gaulejac e Descendre, 1993; entre outros), os quais estimulam a reflexão sobre as organizações como instrumentos de reprodução das relações de dominação de uma sociedade de classes. A referência desses autores ao lado sombrio das organizações assenta-se no modo como grandes corporações produzem danos à sociedade (trabalhadores, consumidores, meio ambiente, comunidades) em nome de seus interesses. Nessa mesma direção, estudos sobre os predadores corporativos (Mokhiber \& Weissman, 1999), as organizações criminosas (Alexander \& Cohen, 1999) e as organizações assassinas (Stokes \& Gabriel, 2010), entre outros, discutem os prejuízos originados nas e pelas organizações.

No centro das reflexões desses autores, inserem-se os crimes corporativos. É nesse espaço sombrio que as interseções entre o poder, a dominação e a ideologia potencializam as formas de exploração e dominação, seja no âmbito do trabalho, do consumo, do meio ambiente, das instituições de modo geral, ou dos governos. Assim, a criminalidade corporativa, ao se situar no lado sombrio das organizações, no âmbito dos estudos organizacionais, demanda perspectivas que busquem o afastamento da visão positivista das organizações e se orientem por uma visão desafiadora das estruturas de dominação, questionadora de práticas institucionalizadas, desvinculada da performance organizacional, e, portanto, dotada de reflexividade (Alvesson \& Deetz, 2000).

Entre as perspectivas que se encontram distantes da visão positivista, a abordagem político-econômica ou radical (Michalowski \& Kramer, 2007) e a crítica ideológica (Alvesson \& Deetz, 2000) apresentam-se como aquelas capazes de subsidiar o questionamento do conhecimento já existente sobre os crimes corporativos. A primeira abordagem, consoante como conceito de capitalismo tóxico (Pearce \& Tombs, 1999), centra-se no questionamento da estrutura político-econômica do sistema capitalista, a partir da qual emergem os crimes corporativos.

A crítica ideológica, conforme Alvesson e Deetz (2000), tem sua origem na análise de Marx sobre os processos de trabalho, cujo foco são as práticas de exploração econômica e as diferenças estruturais entre empregados e empregadores. Essa perspectiva tem como temas centrais a dominação e exploração por parte dos proprietários e gerentes, e inspirou teóricos organizacionais, como Willmott (1990), entre outros, que ampliaram as análises deslocando-as para cobrir outras preocupações, como o controle cultural-ideológico. A lógica capitalista é, então, o núcleo da crítica ideológica, bem como da abordagem político-econômica. Assim, faz sentido a análise dos crimes corporativos orientada pela crítica ideológica, no sentido de desafiar o conhecimento construído em torno do que seja crime corporativo com vistas a ocultar os interesses da corporação.

Um esforço adicional para compreender a criminalidade corporativa pode ser realizado tendo como âncora a perspectiva da crítica pós-colonialista, uma abordagem que assume diferentes posições (ver Prasad, 2003; Westwood, 2006; Young, 2001). Westwood (2006, p. 93) descreve o "pós-colonialismo como uma análise da linguagem e do discurso do imperialismo, como uma recuperação das vozes silenciadas daqueles marginalizados e oprimidos através do colonialismo ou uma crítica da noção imposta de estado nação, que desmantela os mitos do desenvolvimento". Em síntese, essa teoria analisa não apenas as relações entre colonizador e colonizado, mas lança seus olhares para o modo como a construção do primeiro ocorre por meio da fabricação do segundo, em condições de hierarquização e outremização, o que pode ser utilizado para a análise da atuação das transnacionais em países periféricos, por exemplo.

A noção de discurso na teoria pós-colonial é, pois, capaz de iluminar as questões que envolvem o contexto do exercício do poder imperial e as imbricações mútuas do material e do ideológico, como faz Banerjee (2008) para desenvolver o conceito de necrocapitalismo: "formas contemporâneas de acumulação organizacional que envolvem a desapropriação e a subjugação da vida ao poder da morte" (Banerjee, 2008, p. 1541). Esse autor debruça-se nos processos históricos que constituem o imperialismo e o colonialismo e ressalta o modo como esses sustentaram a expansão do capitalismo, visto que ambos representam formas de dominação, acumulação e exploração de territórios, seja de maneira informal ou formal. Ao resgatar tais processos, Banerjee (2008) justifica a importância de se examinarem as relações entre as nações, instituições internacionais e 
corporações transnacionais para descortinar a presença do imperialismo nas estruturas e processos institucionais e, assim, sustentar a ideia de que existe um tipo de capitalismo contemporâneo que subjuga a vida, que é o necrocapitalismo.

Esse autor explica que as fronteiras de territórios e nações, a despeito das noções de independência e suprema autoridade dos estados-nações, têm sido transgredidas por "formações imperiais" - uma condição para o necrocapitalismo, e um colonialismo que representa, nas palavras de Banerjee (2008, p. 1545), "um estado de exceção permanente, em que a soberania torna-se um exercício de poder fora da lei”, em que as corporações transnacionais parecem operar com impunidade (Pearce \& Tombs, 1999).

A transgressão da soberania na Era Pós-Colonial, para utilizar os termos de Banerjee (2008), ocorre na esteira das políticas neoliberais e do entrelaçamento de governos, agências e corporações transnacionais que regulam a economia, o mercado e o sistema sociocultural de territórios periféricos, ficando a soberania política subserviente à soberania econômica da corporação. É nesse sentido que a abordagem pós-colonialista oferece uma alternativa para a análise dos crime corporativos. Banerjee (2008, p. 1549) entende que a corporação "é um ator poderoso junto com estados nações, organismos supranacionais, e agências internacionais para uma privatização necrocapitalista da soberania”. Assim, os crimes corporativos são produzidos, também, como uma ação planejada. Para Banerjee (2008), o necrocapitalismo envolve práticas realizadas por um conjunto de atores que se interlaçam para criar um processo de produção da morte, sendo assim, faz-se necessária uma compreensão mais profunda sobre essas práticas, a qual se centre em questões como: Quem são os atores envolvidos? Como se planeja a produção da morte? Quais são as armas empregadas? Como se obtém o consentimento para produzir as mortes?

A utilização de paradigmas diferentes tem recebido apoio (ver Lewis \& Grimes, 1999) no que concerne à possibilidade de desenvolver pesquisa e, consequentemente, gerar conhecimento a partir de perspectivas divergentes. Ainda segundo, lançar mão de uma pesquisa multiparadigmática permite reconhecer o foco e as limitações impostas por lentes de paradigmas divergentes, cultivar suas representações contrastantes e acomodar seus díspares insights. Apoiados nessas justificativas, defendemos que abordagens combinadas oferecem explicações quanto à criminalidade corporativa que ocorre pela exploração e dominação das corporações, bem como sinalizam para as possibilidades de desafiar suposições básicas a respeito dos crimes corporativos, indo, assim, rumo à mudança social.

\section{CONSIDERAÇÕES FINAIS SOBRE CRIMES CORPORATIVOS E O CAMPO DOS ESTUDOS ORGANIZACIONAIS}

Para alcançar nosso objetivo, exploramos as pesquisas sobre crimes corporativos buscando situar esse tema no campo dos estudos organizacionais, o que fizemos considerando o lado sombrio das organizações, visto que este não faz parte dos conceitos e explicações disponíveis nesse campo que compreende, predominantemente, o lado que brilha. Apresentamos uma síntese das várias pesquisas sobre crimes corporativos no âmbito internacional localizadas na sociologia e criminologia e percebemos uma lacuna existente no âmbito dos estudos organizacionais, embora muitas dessas pesquisas tenham se utilizado de perspectivas da teoria das organizações.

Ao situar o tema no campo dos estudos organizacionais, compreendemos que a perspectiva modernista não é suficiente para a análise dos crimes corporativos, o que nos levou a propor referenciais críticos para a pesquisa do tema. Encontramos, na crítica ideológica e na crítica pós-colonial, um caminho a trilhar na condução de pesquisas que questionem a ocorrência dos crimes corporativos como uma prática planejada nas operações da corporação, e não como um incidente ou algo não intencional, que seja explicado por uma relação de causa e efeito ou pela busca do progresso.

Nosso artigo traz duas principais contribuições: primeiro, ao oferecer uma síntese das pesquisas sobre crimes corporativos e situá-las no campo, ampliamos as possibilidades de pesquisas no âmbito dos estudos organizacionais; e, segundo, sinalizamos para a riqueza em se vincularem pesquisas sobre o tema à matriz dos estudos pós-colonialistas, visto que as corporações transnacionais escolhem países periféricos para suas operações, que colocam em perigo e risco a segurança e a vida de populações e o meio ambiente.

Considerando as potencialidades dessas contribuições, apresentamos sugestões para pesquisas: (1) pesquisar, comparativamente, crimes corporativos cometidos por corporações em países periféricos e centrais; (2) focalizar as articulações engendradas entre os atores envolvidos na produção dos crimes corporativos; (3) considerar a Filosofia, especificamente, as noções de moral, ética e cultura, e suas contribuições para essas reflexões; e (4) pesquisar os movimentos de recusa às imposições das corporações para atuarem de maneira criminosa, buscando identificar aspectos centrais da sua criação e desenvolvimento, interpretando as relações sociais que tornam possível a transformação de ações conformistas em ações de luta.

Finalizando, ressaltamos que, frequentemente, cidadãos, comunidades, a fauna e a flora, bem como os recursos naturais, correm sérios riscos quando o lucro, o poder e a influência das cor- 
porações são colocados acima da vida em busca de interesses corporativos. Lembrando o pensamento de Hannah Arendt, analogamente, em uma sociedade onde isso é permitido, tudo é possível.

\section{NOTA DA AUTORA}

Esta pesquisa contou com o apoio da Fundação de Amparo à Pesquisa do Estado de Minas Gerais (FAPEMIG).

\section{REFERÊNCIAS}

Alexander, C. R, \& Cohen, M. A. (1999). Why do corporations become criminals? Ownership, hidden actions, and crime as an agency cost. Journal of Corporate Finance, 5, 1-34.

Alvesson, M, \& Deetz, S. (2000). Doing critical management research. London: Sage.

Ashforth, B. E., Gioia, D. A., Robinson, S. L. \& Treviño, L. K. (2008) Re-viewing organizational corruption. Academy of Management Review, 33 (3), 670-684.

Banerjee, S. B. (2008). Necrocaptalism. Organization Studies, 29(12), 1541-1563.

Baucus, M. S. (1994). Pressure, opportunity and predisposition: a multivariate model of corporate illegality. Journal of Management, 20(4), 699-721.

Baucus, M. S, \& Near, J. P. (1991). Can illegal corporate behavior be predicted? An event history analysis. The Academy of Management Journal, 34(1), 9-36.

Braithwaite, J. (1985). White-collar crime. American Review of Sociology, 11, 1-25.

Clinard, M. B., Yeager, P. C, Brissette, J, Petrashek, D \& Harries, E. (1979). Illegal corporate behavior. Washington: U. S.: Department of Justice.

Coleman, J. W. (1987). Toward an integrated theory of white-collar crime. The American Journal of Sociology, 93(2), 406-439.

Cooper, R,\& Burrell, G. (1988). Modernism, postmodernism and organizational analysis: an introduction. Organization Studies, 9(1), 91-112.

Costa, A. P. P. Da, \& Wood, T, Jr. (2012). Fraudes corporativas. RAE-revista de administração de empresas, 52 (4), 464-472.

Daboub, A. J, Rasheed, A. M. A, Priem, R. L, \& Gray, D. A. (1995). Top management team characteristics and corporate illegal activity. Academy of Management Review, 20(1), 138-170.

Enriquez, E. (1997). A organização em análise. Petrópolis: Vozes.

Freitas, M. E. (2005). Existe uma saúde moral nas organizações? Organizações e Sociedade, 12(32), 13-27.

Geis, G. (1991). White collar crime. What is it? Current Issues in Criminal Justice, 3(1), 9-24.

Kramer, R. C. (1984). Corporate criminality: the development of an idea. In E. Hochstedler (Ed.). Corporation as criminal. Beverly Hills: Sage Publications.

Lewis, M. W, \& Grimes, A. J. (1999). Metatriangulation: building theory from multiple paradigms. The Academy of Management Review, 24(4), 672-690.

MacLean, T. L. (2008). Framing and organizational misconduct: a symbolic interactionist study. Journal of Business Ethics, 78, 3-16.
McKendall, M. A, \& Wagner, J. A, III. (1997). Motive, opportunity, choice, and corporate illegality. Organization Science, 8(6), 624-647.

Michalowski, R. J, \& Kramer, R. C. (2007). State-corporate crime and criminological inquiry. In H. N. Pontell, \& G. L. Geis (Eds.). International handbook of white-collar and corporate crime. Irvine-Ca: University of California.(Cap. 2, pp. 200-219).

Mokhiber, R, \& Weissman, R. (1999). Corporate predators. The hunt for mega-profits and the attack on democracy. Maine: Courage Press.

Mon, W. (2002). Causal factors of corporate crime in Taiwan: qualitative and quantitative findings. International Journal of Offender Therapy and Comparative Criminology, 46(2), 183-205.

Morgan, G. (1996). Images of organization. London: Sage Publications.

Motta, F. C. P. (1992, novembro-dezembro). Organizações, vínculo e imagem. RAE. Revista de Administração de Empresas, 31(3), 5-11.

Ortega, B. (1999). In Sam we trust: the untold story of Sam Walton and Wal-Mart, the world's most powerful retailer. Londres: Kongan Page.

Pagès, M., Bonetti, M., Gaulejac, V., \& Descendre, D.. (1993). O poder das organizações: a dominação das multinacionais sobre os indivíduos. São Paulo: Atlas.

Payne, B. K. (2012). White-collar crime. The essentials. Georgia: Sage Publications.

Pearce, F, \& Tombs, S. (1999). Toxic capitalism: corporate crime and the chemical industry. Toronto: Canadian Scholars' Press.

Prasad, A. (2003). Postcolonial theory and organizational analysis: a critical reader. New York: Basingstoke, Palgrave Macmillan.

Reed, M. (1996). Organizational theorizing: a historically contested terrain. In S. R. Clegg, C. Hardy, \& W. R. Nord (Ed.). Handbook of organization studies (Vol. 1, pp. 31-56). London: Sage.

Shover, N, \& Hochstetler, A. (2002). Cultural explanation and organizational crime. Crime, Law \& Social Change, 37, 1-18.

Snider, L. (2000). The sociology of corporate crime: an obituary: (or: whose knowledge claim have legs?). Theoretical Criminology, 4(2), 169206.

Stokes, P, \& Gabriel, Y. (2010). Engaging with genocide: the challenge for organization and management studies. Organization, 17(4), 461-480.

Sutherland, E. (1949). White-collar crime. New York: Holt, Rinehart \& Winston.

Sutherland, E. H. (1940). White-collar criminality. American Sociological Review, 5(1), 1-12.

Sutherland, E. H. (1941). Crime and business. Annals of the American Academy of Political and Social Science, Crime in the United States, Philadelphia, 217.

Szwajkowski, E. (1985). Organizational illegality: theoretical integration and illustrative application. The Academy of Management Review, 10(3), 558-567.

Westwood, R. (2006). International business and management studies as an orientalist discourse: a postcolonial critique. Critical Perspectives on international Business, 2(2), 91-113.

Willmott, H. (1990). Beyond paradigmatic closure in organizational enquiry. In J. Hassard, \& D. Pym. The theory and philosophy of organizations. Critical issues and new perspectives (pp. 44-60). London: Routledge.

Young, R. (2001). Postcolonialism: an historical introduction. Oxford: Blackwell.

Zahra, S. A, Priem, R. L, \& Rasheed, A. A. (2005). The antecedents and consequences of top management fraud. Journal of Management, 31(6), 803-828. 